\title{
Revista
}

(Rgpp) Gestão \& Políticas Públicas

Artigo

\section{A Economia Criativa No Brasil: Da Gênese, Ferramentas Políticas aos Desafios Futuros}

The Creative Economy in Brazil: From Genesis Policy Tools to Future Challenges

La economía creativa en Brasil: En Herramientas Política de Génesis a los desafíos futuros

Felipe Gonçaves Brasil ${ }^{1}$, Renan do Prado Alves ${ }^{2}$, Joice do Prado Alves ${ }^{3}$

\footnotetext{
${ }^{1}$ Filiação institucional. Bacharel em Gestão de Políticas Públicas pela Universidade de São Paulo, mestre e doutorando pelo Programa de Pós-Graduação em Ciência Política da Universidade Federal de São Carlos, São Carlos, SP, Brasil. Correspondência: E-mail: fbrasil.pp@gmail.com

${ }^{2}$ Filiação. Bacharel em Administração Pública pela Universidade Estadual Paulista "Júlio de Mesquita Filçho, Araraquara, mestrando pelo Programa de Pós-Graduação em Ciência Política da Universidade Federal de São Carlos, São Carlos, SP, Brasil.

Correspondência: $\quad$ E-mail: pradoalvesr@gmail.com

3 Filiação institucional. Mestre em Educação pela Universidade Federal de Pelotas (UFPel), com desenvolvimento de pesquisas ligadas a cultura, representações e estética cinematográfica.

Correspondência: $\quad$ E-mail: joiceprado@yahoo.com.br
}

Resumo Este trabalho tem como objetivo fazer uma revisão histórica e bibliográfica acerca da Economia Criativa, desde seu nascimento até sua implantação no cenário brasileiro. Através dessa retrospectiva histórica, pretende-se apontar as principais dificuldades e perspectivas para este ramo que se encontra em estágio incipiente no Brasil, apesar do recente crescimento institucional e do aumento do fomento financeiro. A justificativa cerceia o fato da literatura sobre a economia criativa no Brasil ser extremamente escassa, se limitando a artigos baseados em estudos de caso e a própria legislação e planos da Secretaria de Economia Criativa (SEC). Dessa forma, pretende-se auxiliar o fomento deste ramo em franca expansão e que conta com baixa análise teórica. 
Palavras-chaves: Economia criativa. Política Pública. Políticas Culturais. Políticas de Cultura no Brasil.

Abstract This paper aims to make a historical and bibliographical review on the Creative Economy, from its birth to the implementation of this in the Brazilian scenario. Through this historical review, we intend to point out the main problems and prospects for this branch is in an incipient stage in Brazil, despite the recent institutional growth and increased financial incentives. The justification curtails the fact the literature on the creative economy in Brazil is extremely sparse, limited to articles based on case studies and legislation itself and plans of the Department of Creative Economy (SEC) of. Thus, we intend to help the promotion of this business booming and has low theoretical analysis.

Keywords: Creative Economy, Public Policy, Cultural Policy, Cultural Policies in Brazil.

Resumen Este trabajo tiene como objetivo hacer una revisión histórica y bibliográfica sobre la Economía Creativa, desde su nacimiento hasta su implementación en la escena brasileña. A través de esta retrospectiva histórica, los principales problemas y perspectivas tiene la intención de apuntar a esta rama está en una etapa temprana en Brasil, a pesar del reciente crecimiento institucional y el aumento de los incentivos financieros. La justificación cercena el hecho de que la literatura sobre la economía creativa en Brasil es extremadamente escaso, limitado a artículos basados en estudios de casos y la propia legislación y los planes de la Secretaría de Economía Creativa (SEC). Así, se pretende contribuir al desarrollo de esta rama en auge y tiene bajo análisis teórico.

Palabras Clave: Economía creativa, Política Pública, Las políticas culturales, Políticas de Cultura en Brasil. 


\section{A cultura e a economia criativa no mundo: histórico, conceitos e atualidade}

Durante boa parte da história da humanidade, as questões culturais estiveram mais relacionadas à ordem privada da vida dos indivíduos do que conectadas a temas associados à economia. Porém, com a percepção do homem de que o capital econômico não é gerado apenas pelas atividades industriais clássicas (tais como as siderúrgicas, têxteis, etc.), mas também pela comercialização de símbolos e atividades baseadas na criatividade individual e coletiva, recentemente observa-se que a cultura passa a ser objeto privilegiado de atenção do campo econômico (MIGUEZ, 2007, p. 96).

Exemplos disso podem ser observados em áreas como as indústrias têxteis, onde a moda causa impactos tangíveis, ou mesmo no setor alimentício, onde a gastronomia termina por influenciar fortemente. Se pensarmos na própria noção de consumo de bens atualmente, fica claro que tal noção se apoia muito mais na cultura do que necessariamente nos campos econômicos ou políticos. Como mostra George Yudice (2004, p.34-35): “A noção de cultura sofreu várias mutações para satisfazer as exigências do resultado final [...] e alguns até defendem que a cultura se transformou na própria lógica do capitalismo contemporâneo"

O termo "cultura" é sem dúvida uma acepção complexa que inclui "o conhecimento, as crenças, a arte, a moral, a lei, os costumes e todos os outros hábitos e capacidades adquiridos pelo homem como membro da sociedade" (TYLOR, 1903, p. 01). É dentro desse imbricado campo de estudo que influencia e deixa-se influenciar por diversos outros setores sociais que enfocamos aqui o estudo e análise da economia criativa.

Tal modelo surgiu entre as décadas de 1980 e 1990 nos Estados Unidos, sendo propagado para o Reino Unido e Austrália nos anos subsequentes. Nascida como uma medida da classe artística norte-americana para justificar o valor econômico de seus produtos e serviços, essa medida causou um grande impacto econômico no sentido de que os bens culturais intangíveis começaram a ter valor agregado (LANDRY, 2011, p. 07).

Assim, se levarmos em conta as enormes somas de dinheiro investidas nos laços que unem cultura e consumo a partir de então (seja nas industrias musicais, cinematográficas, etc.), temos que no início do século XXI "a arte se dobrou inteiramente a um conceito expandido de cultura" (YUDICE, 2004, p.28).

A noção de uma economia criativa (justamente um setor que tem a habilidade de explorar economicamente novas ideias baseadas no seguimento cultural), ganhou destaque quando o Partido Trabalhista Inglês (New Labor Party) apresentou soluções baseadas na economia criativa nas eleições de 1997. Com o sucesso do partido trabalhista (personificado na figura do primeiro ministro Tony 
Blair) a economia criativa ganhou peso e representação governamental dentro do Departamento de Cultura, Mídia e Esportes (DCMS) da Inglaterra.

John Howkins, autor do já clássico "Creative Economy: How People Make Money From Ideas" (2001) define a economia criativa como o setor que tem a habilidade de gerar coisas novas e que podem ser exploradas economicamente. Isso quer dizer que as produções de uma ou mais pessoas devem ser pessoais, originais e significativas, já que a economia criativa acontece quando alguém diz ou faz algo novo (HOWNKINS, 2001). Por sua vez, o Departamento de Cultura, Mídia e Esportes do Reino Unido a define como sendo:

[...] aquela indústria que têm sua origem na criatividade individual, habilidade e talento e que têm um potencial de riqueza e criação de emprego através da geração e exploração da propriedade intelectual (DCMS, 1998, p.3).

A Conferência das Nações Unidas sobre Comércio e Desenvolvimento (UNCTAD) realizada em 2008, afirma ser a economia criativa um conceito em evolução e que traz em suas bases ativos criativos potencialmente geradores de crescimento e desenvolvimento econômico. O que fica claro, nesse sentido, é que a visão de que ideias criativas e inovadoras podem ser associadas a uma produção econômica vem ganhando cada vez mais atenção, tornando a economia criativa uma forma de produção nova e sustentável.

O relatório do Creativity Economy (2010 - UNCTAD) estima que a economia criativa (incluindo os setores moda, design, fotografia, cinema, rádio, tevê, vídeo, arquitetura, artes visuais, desenvolvimento de softwares, mídia, gastronomia, teatro editoração, propaganda, artesanato, musica) compõe a terceira maior indústria do mundo, atrás apenas das indústrias de petróleo e armamentos. Este relatório traz uma abordagem detalhada do estágio da economia criativa em diversas regiões do mundo, mostrando as vantagens e desvantagens de investimento no setor ${ }^{4}$. Amostra disso é o continente africano, onde nota-se, por exemplo, que a comercialização de produtos culturais é limitada, sendo que a maioria da produção artística centra-se no comércio informal.

Esse cenário é problemático, pois inicia um efeito "dominó" que gera desinteresse por parte dos artistas, levando-os a preferirem trabalhar fora de seus países e criando um ciclo vicioso. Ainda assim, vemos países como Moçambique, Egito e Senegal, procurarem fomentar políticas públicas baseadas na economia criativa, visando justamente a geração de renda e, consequentemente, a diminuição da pobreza.

\footnotetext{
${ }^{4}$ O relatório traz uma análise de seis regiões do mundo, sendo elas a África, Ásia-Pacífico, Ásia Central/ Oriente Médio, América Latina, Caribe e Europa Oriental
} 
Do outro lado do prisma, a América Latina vem demonstrando um considerável aumento nas práticas econômico-criativas de forma articulada entre os países, o que propicia uma melhor integração cultural. Dessa forma, tem-se um panorama das riquezas culturais individuais que podem ser intercambiáveis com outras nações.

\section{A institucionalização da Economia Criativa no Brasil}

No cenário global, a constituição do termo "economia criativa" data da década de 1990 e nasce como uma forma de produção alternativa dentro de um mundo com grandes resquícios fordistas (PIRES; ALBAGLI, 2012, p. 112). Como já abordado, temos que as empresas privadas, por exemplo, começaram a enxergar no campo das Artes novos caminhos inovadores com lastros sustentáveis de produção e renda.

No Brasil, entretanto, a economia criativa só se firma como política governamental no final de 2010, com a publicação do Plano Nacional de Cultura, publicação que coloca como meta a escrutinação dos segmentos culturais criativos.

Para entender o advento tardio da economia criativa em território brasileiro, é importante fazer uma retrospectiva histórica da importância e do lugar ocupado pela "cultura" no contexto nacional.

Diversos são os autores que identificam, desde o período colonial, um legado que enraizou aspectos sociais, políticos, econômicos e culturais, refletidos, ainda hoje, na sociedade brasileira (FAORO, 2001; HOLLANDA, 1995). Rubim (2012) afirma que a cultura nacional brasileira sempre foi um tanto quanto peculiar, principalmente por conta das grandes transformações que assolaram a então cultura indígena e integraram ao cenário nacional uma cultura tipicamente europeia, causando uma transição abrupta de valores.

O período imperial não traz grandes mudanças para o segmento, uma vez que o governo continuou a preferir os privilégios da nobreza em detrimento do direito da sociedade civil. Essa realidade só começa a mudar com o fim da República Velha (1930) e compreende marcos como a instalação do Ministério da Educação e Cultura (1953) e a expansão das universidades brasileiras.

Após esse período, dividido entre autoritarismo e democracia, a instalação do período militar brasileiro significa uma retração na questão cultural uma vez que intelectuais, artistas, cientistas, entre outros, foram reprimidos, censurados, perseguidos e assassinados pelos militares (RUBIM, 2012). O ápice da repressão política e cultural brasileira se deu com o ato institucional $\mathrm{n} 05$ que considerava os atos subversivos oriundos dos mais distintos setores políticos e culturais como 
meios de combater e destruir o desenvolvimento e bem-estar da nação (BRASIL, 1968).

Com a queda dos militares, a cultura passou então a ganhar novo espaço na agenda governamental. Tendo se separado do Ministério da Educação, o setor cultural brasileiro se institucionalizou e ganhou força. Assim, o Ministério da Cultura (MinC), criado em 1985 pelo decreto no 91.144, fez com que a cultura fosse reconhecida como um elemento fundamental e insubstituível na construção da identidade nacional (MINISTÉRIO DA CULTURA, 2013).

Após essa retomada histórica, o que percebemos é que a cultura no Brasil sempre foi tratada como um elemento secundário na agenda governamental. As questões territoriais, a construção do Estado, a influência do desenvolvimento econômico e industrial que sempre buscaram reverter o atraso e o capitalismo tardio foram processos que refletiram na construção e consolidação da cultura em nosso país.

Esse cenário ajuda a explicar o estágio incipiente das políticas culturais brasileiras, bem como a baixa adesão às políticas de economia criativa (quando comparado às experiências de outros países com trajetórias distintas) Como mostram Vieira e Simões (2010):

Ao refletir-se a respeito da atual situação da cultura no Brasil parece ser evidente que esta - considerando-se os diversos problemas sociais e econômicos do país - não foi a pauta central nem da sociedade nem do mercado, tampouco foi uma prioridade governamental ao longo do tempo (SIMÕES e VIEIRA, 2010, p. 217).

Nesse sentido, o recente advento da economia criativa em terras nacionais se revela como uma válvula de escape para o setor cultural que, ao longo de sua história, encontrou dificuldades para se firmar institucionalmente, passou por diversas reestruturações e processos de descontinuidade de gestão, o que afetou a propagação de políticas culturais nacionais (CALABRE, 2007).

Curiosamente, no Brasil, os primeiros ensaios sobre o conceito de economia criativa aparecem no pensamento do economista (e então Ministro da Cultura) Celso Furtado já no final da década de 1970, muito antes da consagração da economia criativa na década de 1990, na Inglaterra. No seu livro "Criatividade e Dependência na Civilização Industrial" o autor, ao tratar da industrialização das periferias, afirma que as relações econômicas modernas “já não se tratam de reproduzir o que existe, e sim de ampliar o campo do que é imediatamente possível [...]" (FURTADO, 1978). Dessa forma, aponta que a saída para os países periféricos - que tiveram sua industrialização tardia -, é justamente investir naquilo que pode ser gerado através da cultura de um povo e, principalmente, através da criatividade humana.

Entretanto, apenas em 2004 é que o termo "economia criativa" ganhou força no Brasil, principalmente através da realização da XI Conferência da 
UNCTAD. Esse evento uniu esforços para discutir assuntos referentes a relação entre comércio e indústrias criativas, apontando os novos caminhos e as recentes políticas públicas que trabalham com o tema (TORTORA, 2014, p. 18).

Em 2008 o assunto entrou de fato na pauta do comércio brasileiro, após a publicação do estudo "A Cadeia da Indústria Criativa no Brasil", em 2008, pelo Sistema FIRJAN (Federação das Indústrias do Estado do Rio de Janeiro). Fazendo uma análise bastante regional e apoiada fortemente em modelos criativos estrangeiros, o estudo acabou se tornando um referencial importante para criação da Secretaria de Economia Criativa, no Ministério da Cultura, em 2012.

Em termos governamentais, um importante balizador da economia criativa foi o Plano Nacional de Cultura (PNC) que, apesar de ter entrado na pauta federal no final dos anos 1980 através da Constituição Federal de 1988, só foi efetivamente criado em 2010.

O PNC se tornou responsável por promover o "desenvolvimento cultural do País e à integração das ações do poder público que conduzem defesa, produção, democratização e valorização dos bens culturais nacionais" (BRASIL, 1988, p. 158-159). Formuladas em âmbito nacional e tendo sua implementação descentralizada para estados e municípios, as 53 metas que compõe o documento e referenciam as ações do Plano devem ser atingidas até 2020. Deve ficar claro a importância deste Plano, pois ele é um ponto chave na institucionalização da economia criativa. Afinal, é através do PNC que a cultura ganha destaque e se consolida como uma demanda governamental e popular.

Institucionalmente, a economia criativa se consolida no Brasil com a criação da Secretaria de Economia Criativa (SEC) em 2012. Segundo o decreto no 7743 de 1 ㅇ de junho de 2012, é de competência da SEC:

[...] propor, conduzir e subsidiar a elaboração, implementação e avaliação de planos e políticas públicas para o desenvolvimento da economia criativa brasileira; planejar, promover, implementar e coordenar ações para o desenvolvimento da economia criativa brasileira; formular e apoiar ações para formação de profissionais e empreendedores criativos e qualificação de empreendimentos dos setores criativos (BRASIL, 2012, p. 04).

Além disso, a SEC tem a missão de "conduzir o desenvolvimento local e regional, priorizando o apoio e o fomento aos profissionais e aos micro e pequenos empreendimentos criativos brasileiros". (BRASIL, 2011, p. 39). 


\section{Ferramentas utilizadas e o Desenho da política de Economia Criativa no Brasil}

Uma das questões que chamam a atenção quando olhamos o processo institucionalizaçao da Economia Criativa no Brasil, refere-se às ferramentas einstrumentos que moldam o design dessa política. Inserido no de formulação de políticas, a escolha de instrumentos e ferramentas políticas (policy tools) são elemento importante que influenciam o alcance e os meios pelos queis os objetivos pretendidos poderão ser alcançados (Peters, 2000; Smith e Ingram, 2002). Portanto, identificar os tipos de ferramentas presentes em uma política pode indicar a forma como os decisores políticos identificaram um problema e selecionaram as opções para soluioná-lo (Hood, 1986). Assim, a escolha e design dos instrumentos de política pode produzir tanto a distância como a aproximação dos objetivos originais.

Diferente dos modelos anglo-saxão, australiano ou asiático, que se pautam na ideia de Indústrias Criativas e no conceito de propriedade, conceito esse ligado ao copyright, o modelo criativo brasileiro apoia cinco grandes campos, dentro dos quais há as subdivisões específicas dos temas abordados. Se no modelo anglo-saxão a principal ferramenta utilizada é a do fomento de criação de mercado, entendido em perspectiva industrial, como propriedade, as ferramentas para desenhar a política de fomento a Economia Criativa no Brasil parecem ser outras. Menos "industriais" os mecanismos e forma de atuação parecem envolver questões sociais e políticas sem, no entanto, abandonar os preceitos econômicos.

É preciso ter claro que a Economia Criativa somente se torna viável num contexto de desenvolvimento sustentável com liberdade e abundância, diferente da Economia Industrial que se funda no modelo econômico Taylorista da escassez e da restrição como lógica de valor da Sociedade Industrial. (WACHOWICZ, M.; CRUZ E SILVA, 2011, p. 564)

A atuação da SEC é feita por meio de uma rede de propostas em diversos setores. Da publicação de editais com incentivos financeiros, ao custeio de bolsas de estudos, participação em eventos ou mesmo na ação direta, questões como a descentralização, a participação popular e a ampliação do eixo cultural como desenvolvimento social e político. A "economia" gerada por meio desses incentivos, não busca o registro e patente de ideias, mas sim o reconhecimento e empoderamento mais subjetivos de setores historicamente preteridos na atenção do Estado no Brasil.

No campo do patrimônio, se fomenta o patrimônio material, imaterial, arquivos e museus. Já no setor das expressões culturais, estimula-se o artesanato, as culturas populares, indígenas e afro-brasileiras, além das artes visuais e digitais. Por sua vez, no campo das artes de espetáculo, promove-se a dança, a música, o circo e o teatro. Na categoria do audiovisual/livro e leitura, 
desenvolve-se políticas de cinema, vídeo e de publicações e mídias impressas. Por fim, no campo das criações funcionais, fomenta-se a moda, o design e a arquitetura (BRASIL, 2011, p. 30).

Assim, a partir do entendimento de que a Economia Criativa promove o desenvolvimento sustentável e humano, de forma inclusiva social e tecnologicamente, não se trata de uma visão de mero crescimento econômico. Isto porque os novos conceitos inerentes à Economia Criativa alcançam o uso das ferramentas tecnológicas (TICs) na suas interfaces com a educação, a arquitetura, o design, a formação de agentes criativos, os Arranjos Produtivos Locais (APL) e os Setores Criativos (SCs). (WACHOWICZ, M.; CRUZ E SILVA, 2011, p. 563)

Nessa perspectiva, ferramentas tecnológicas, criação de setores criativos e arranjos produtivos locais necessitam de estratégias e de formas de atuação complexas, diferentes dos instrumentos que poderiam ser utilizados caso os objetivos fossem distintos, como no caso da Indústria Criativa. Isso nos faz pensar na concepção de ferramentas para a democracia, obra de Smith e Ingram (2002). Os autores afirmam que a escolha dos instrumentos de política é fundamental para a relação entre o governo e os cidadãos e que as mesas ferramentas podem, num determiando contexo e numa determinada política, afetar diferentes dimensões da governança. Ao explorar as consequências sobre a utilização de determinados tipos de ferramentas para a democracia, eles discutem sobre a importância do desenvolvimento de arranjos políticos mais sensíveis ao impacto cívico.

De acordo com Howlett, Ramesh e Perl (2009) uma série de estudos produziram tipologias de instruemntos, taxonomias, para sua prescrição de avaliação de desenhos de políticas (policy-design). Entre elas, podemos listar as arenas Lowi (1966; 1972); o modelo "NATO" (Hood, 1986); ou mesmo a tipologa que subdivide as ferramentas em 14 tipos básicos, elaborada por Salamon (2002).

Baseado na tipologia "NATO", as ferramentas podem ser separadas e agrupadas de acordo com sua nodalidade, tesouro, autoridade e organização (Hood, 1986). A nodalidade mostra a capacidade do governo para operar como um nó (um ponto focal) em uma rede de informação, utilizando-se de recursos informacionais como campanhas de informação pública, elaboração de campanhas e convencimento. Os instrumentos de "tesouro" denotam aqueles recursos do governo utilizados como incentivos, desencentivos financeiros, ou intervenção na criação de grupos de intersse, think thank, etc. (Hood, 1986, Howlett, Ramesh, Perl, 2009)

Segundo Lasswell, "Autoridade denota a posse do poder legal ou oficial" (Lasswell, 1950, p.76). Esse é o poder oficial de regulamentar; criar condicionalidades, dar maior ou menos autonomia aos atores; atuar na intervenção direta ou indireta e na natureza dos ajustes. Por fim, os instrumento 
Organização considerarm a maneira o Governo age: seja pela prestação direta, por meo de parcerias, pelo fomento a criação de mercado, designação ao voluntariado e ações comunitárias, etc.

Ao analisarmos as formas de atuação e os objetivos da Secretaria de Economia Solidária, podemos entender o complexo design que essa política apresenta e, principalmente, os desafios de coordenação de uma política descentralizadora que, mais do que agregar valor econômico, busca fomentar o desenvolvimento sustentável, combatendo as desigualdades regionais e sociais decorrentes de um longo processo de subalternização das culturas locais, dando autonomia e capacidade de atuação aos atores locais.

\section{Desafios e Perspectivas}

Em entrevista ao Centro de Pesquisa e Formação do SESC São Paulo, a exsecretária da SEC, Cláudia Leitão, afirmou que o modelo brasileiro não tem uma definição fechada, mas que o arquétipo nacional não visa as indústrias criativas, e sim os pequenos (e até informais) polos criativos culturais. Concomitante a esses balizadores, os projetos apoiados devem seguir quatro máximas da economia criativa nacional: devem ser inovadores, sustentáveis, que prezem pela diversidade cultural e pela inclusão social (BRASIL, 2012).

Apesar de contar com um recente incentivo nas práticas relacionas à economia criativa, o Brasil tem desafios e deve lidar com obstáculos para conseguir figurar entre as principais potências econômicas que utilizam-se da criatividade humana para se destacar.

Como afirmado pela doutora Ana Carla Fonseca Reis em entrevista ao Brasil Criativo SEC, o Brasil tem um futuro promissor no campo. Para a pesquisadora, o brasileiro possui um grande leque de ideias, mas para não ficar no plano da abstração, essas ideias devem ser colocadas em debate, para que, por meio de uma discussão colaborativa, essas ideias gerem novos pensamentos e esses pensamentos possam ser colocados em prática. Outro ponto destacado, é que a criatividade humana deve ser melhor aproveitada para que a conciliação entre os preceitos econômicos clássicos e as ideias frutos dessas reflexões possam convergir numa prática criativa responsiva.

Utilizando dados do importante estudo realizado pela FIRJAN em 2008, podemos notar que há uma grande discrepância entre os setores da economia criativa. Enquanto a arquitetura e a moda despontam com mais de 3000 e 2000 mil trabalhadores, respectivamente, as artes cênicas contam com pouco mais de 11 mil trabalhadores no setor. Indo de encontro e complementando os estudos de Costa e Souza-Santos (2011), esses dados não são tão espantosos. Nesse 
momento, temos que ter em mente que a produção de bens imateriais é complexa e necessita, muitas vezes, se apoiar nas indústrias tradicionais, como supracitado. Dessa forma, as indústrias clássicas da engenharia civil e do segmento têxtil conseguem fomentar a economia criativa relacionada a arquitetura e a moda mais fortemente do que a indústria fonográfica relacionada a criatividade musical, por exemplo. Nesse sentido, mais do que repensar a institucionalização de órgãos que lidem com esse assunto, deve-se formular políticas públicas que viabilizem um maior contato entre sociedade e cultura, criando pontes entre esses dois polos.

Institucionalmente, nas Diretrizes para a Economia Criativa 2011-2014, a SEC expõe cinco desafios que o Brasil deve enfrentar nos próximos anos, sendo eles:

- O levantamento de dados e informações da Economia Criativa no Brasil:

Por ser um fenômeno recente, a economia criativa brasileira ainda conta com poucos estudos e os trabalhos feitos utilizam-se, em sua maioria, de dados secundários. Além disso, os estudos partem do princípio da setorialização do tema, impedindo que a economia criativa seja estudada de forma orgânica e completa. Nesse sentido, este trabalho ajuda a suprir a carência de materiais sobre o tema com a finalidade de fomentar o setor. É válido relembrar que, segundo o Plano Nacional de Cultura, $100 \%$ dos segmentos culturais com cadeias produtivas da economia criativa devem estar mapeados até 2020. Dessa forma, espera-se que as pesquisas governamentais possam se aprofundar e prover mais dados e informações sobre a realidade brasileira nos próximos anos.

- Articulação e incentivo ao desenvolvimento de empreendimentos criativos

Se a liberação de crédito (feita por bancos públicos e particulares) é um tópico importante para os empreendimentos tradicionais, a mesma lógica se aplica as empresas criativas, já que a aquisição de insumos é fator essencial em qualquer tipo de negociação econômica. O grande desafio nesse quesito se dá nas dificuldades desses empreendimentos criativos elaborarem garantias claras para justificar o acesso ao crédito. Outro ponto que deve ser citado é o despreparo tanto das empresas fomentadoras em entender a economia criativa quanto da formação de um pensamento administrativo entre os empreendedores, como é explicitado abaixo:

As dificuldades vão desde a incompreensão dos tempos e dinâmicas de funcionamento destes empreendimentos, para a definição de prazos e carências adequados, até uma incompreensão de códigos sociais e culturais dos agentes econômicos atuantes nesses setores. Esta incompreensão também se dá do ponto de vista dos empreendedores e profissionais criativos não afeitos ou despreparados para a gestão de seus próprios empreendimentos. (BRASIL, 2011, p. 36-37) 


\section{- Educação e formação de habilidades criativas}

Para a exploração completa das capacidades da economia criativa, não basta haver regras institucionalmente bem definidas. É preciso que os atores desse processo tenham uma boa base de formação para lidar não somente com os conceitos técnicos e burocráticos da gestão, mas também de preparação e difusão de conhecimentos subjetivos ligados a sensibilidade artística e de habilidades sociais. Nessa concepção, teria-se um profissional completo, já que essas habilidades são polarizadas entre tecnocratas e artistas, cada um detendo apensa o conhecimento intrínseco a ele. Nesse sentido, espera-se a convergência destes dois opostos para que o indivíduo possa fomentar a economia criativa de maneira plena e absoluta

\section{criativos}

- Infraestrutura de criação, produção, distribuição e consumo de produtos

O tratamento setorial que é dado as políticas públicas no Brasil, em algumas situações, vem dificultar o tratamento destas como políticas unas. Nesse sentido, uma das dificuldades de se analisar a política de economia criativa é a extrema heterogeneidade dos setores que compõe o modelo brasileiro. Em outras palavras, as demandas de produção, distribuição e consumo do artesanato é extremamente diferente dos mesmos quesitos no setor eletrônico. Dessa forma, torna-se difícil a "construção de políticas que se adequem a essas diferentes realidades e necessidades" (BRASIL, 2011, p. 37)

\section{- Criação e adequação de marcos legais para os setores criativos}

Por fim, o tratamento burocrático, centralizado e altamente tradicional faz parte do último desafio que o Brasil deve lidar. A falta de direitos trabalhistas para os artistas e a flexibilização de direitos autorais devem ser temas da pauta governamental dos agentes políticos que lidam com a economia criativa no Brasil, pois somente com definições e conceitualizações bem feitas e bem delimitadas, podemos esperar que a economia criativa realmente cresça, lançando o Brasil a novos patamares.

Finalizando esta abordagem sobre os desafios da economia criativa no Brasil, um deles, dentro da atual conjuntura política, econômica e cultural (tanto mundial quanto brasileira) se encontra na questão que cerca os direitos autorais.

Isso porque em um século essencialmente tecnológico, as barreiras físicas vão sendo derrubadas pelos sinais digitais e diminuindo as distancias entre pessoas, corporações, empresas, governo e etc. A facilidade de se obter qualquer tipo de informação ou produto através da internet atualmente mostra bem que proteger intelectualmente os direitos autorais de alguém é uma tarefa difícil e que deve ser reavaliada com urgência.

Se consideramos que a Lei dos Direitos Autorais foi promulgada no Brasil em 1998 (quando a internet era ainda uma ideia em construção), teremos a clara 
noção de que o cenário vivido pelo país era completamente diferente. O domínio massivo das mídias sociais e a utilização de ferramentas como pen drives, leitores digitais, sites de download de músicas, filmes, jogos, etc. que marcam as primeiras décadas do século XXI nos dão a dimensão das enormes mudanças que se operaram no mundo nesses últimos 16 anos e focalizam a imediata necessidade de revisão da Lei $n \times 09.610 / 98^{5}$ que regulamenta os direitos autorais.

Essa discussão, entretanto, se encontra em pauta desde 2005 e apenas esse fato já deixa claro a lentidão da máquina burocrática quando comparada à rapidez de informações que nos cercam atualmente. O cidadão comum não necessita mais esperar que tais discussões sejam lentamente debatidas através de anos, posto que pode ter acesso à educação, cultura, entretenimento e informação de formas muito mais rápidas e imediatas.

Para o funcionamento eficaz de ideias através da economia criativa se faz urgente, portanto, a revisão dos tratos legais entre artistas e editoras, gravadoras e demais indústrias culturais, criando lastros sólidos que se adequem a nova realidade do mundo globalizado e que não prejudiquem nem os artistas e nem o público comum.

A grande questão que se impõem a esse segmento é justamente essa: como garantir um arcabouço político/jurídico que proteja os direitos do artista e que crie, ao mesmo tempo, caminhos viáveis de acesso democrático à essa produção por parte do cidadão comum e facilite assim o desenvolvimento da economia criativa?

Wachowicz e Cruz e Silva (2011, p.53) apontam que essa e tantas outras argumentações favoráveis ou não aos tais questionamentos só conseguiram começar a ser satisfatoriamente respondidas quando, na sociedade informacional, surgirem modelos voltados exclusivamente para os setores criativos.

\section{Considerações Finais}

Ao realizarmos uma análise da economia criativa em seu contexto cultural, político e econômico buscamos pontuar as principais dificuldades e perspectivas desse segmento.

\footnotetext{
${ }^{5}$ A lei 9.610/1998 trata dos direitos autorais referentes a bens móveis. Em seu artigo 5o, é explicitado que a lei se aplica a publicação, transmissão ou emissão, retransmissão, distribuição, comunicação ao público, reprodução, contrafação, editoração, produção e radiofusão de qualquer obra intelectual.
} 
O que fica claro, ao observamos o panorama histórico da economia criativa, é que um número crescente de países em desenvolvimento segue explorando culturalmente novas formas de crescimento econômico. Na América do Sul, e no Brasil mais especificamente, fica bastante visível a grande potencialidade que segue não sendo plenamente aproveitada, já que a fase de ação ainda não sobrepujou a fase de estudos.

Para que essa fase de ação inicie-se, se faz necessário estabelecer e reforçar instituições, nesses países, que garantam mecanismos de financiamento para fortalecer as bases da economia criativa. Além disso, é primordial que haja uma melhor compreensão "do fato de que a política da economia criativa precise ser vista como uma opção de desenvolvimento viável" (UNCTAD, 2010, p.257). Ou seja, enquanto arte e cultura seguirem essencialmente distantes dos diálogos políticos e econômicos e enquanto artistas não encontrarem nas políticas públicas formas de transformarem suas ideias e criatividades em renda, tais ações seguiram em fase de estudos teóricos.

Já existem inúmeros canais de comunicação abertos, por exemplo na forma de editais disponibilizados pelo governo. Entretanto, o que observamos é ainda um distanciamento entre o público alvo e tais fomentos, o que pode ser contornável conforme se esclareça esses novos caminhos de produção, tornando esse acesso mais visível e também mais viável.

Por fim, cabe ressaltar que para o crescimento da economia criativa e a melhor estruturação de suas políticas públicas é necessário que ocorra uma ação coordenada de uma série de agências, não sendo essas orientadas exclusivamente às grandes áreas urbanas, mas também valorizando as possibilidades existentes nas pequenas cidades e comunidades, inclusive nas áreas rurais (UNCTAD, 2010, p. 260).

\section{Referências Bibliográficas}

Botelho, Isaura. (2001). “As dimensões da cultura e o lugar das políticas públicas". São Paulo e Perspectiva.

Brasil. (1988). "Constituição da República Federativa do Brasil”.

Brasil. Ministério da Cultura. (2010). "Plano Nacional de Cultura. Brasília".

Brasil. Ministério da Cultura. (2010). "Sistema Nacional de Cultura”. Brasília.

Brasil. Ministério da Cultura. (2011). "Plano da Secretaria da Economia Criativa: políticas, diretrizes e ações 2011 a 2014". Brasília. 
Calabre, Lia. (2007). "Políticas Culturais no Brasil: balanço e perspectivas". Trabalho apresentado no III ENECULT - Encontro de Estudos Multidisciplinares em Cultura, Faculdade de Comunicação/UFBa, Salvador-Bahia-Brasil.

Durand, José C. (2001). “Cultura como objeto de Política Pública”. São Paulo e Perspectiva.

Faoro, Raymundo. (2001). “Os Donos do Poder: Formação do patronato político brasileiro". 3o Ed. São Paulo: Globos.

Faria, Hamilton., \& Souza, Valmir. (1993). "Os sentidos da cultura na Cidade". In Hamilton Faria. Pólis, no 12, São Paulo. p. 03-07

Furtado, Celso. (2008). "Criatividade e dependência na civilização industrial". Companhia de Letras.

Holanda, Sérgio Buarque. (1995). "Raízes do Brasil”. 26ํ Ed. São Paulo: Companhia das Letras. p. 217.

Hood, Christopher. (1986). "The Tools of Government". Chatham, Chatham House Publisher.

Howkins, John. (2001). "The Creative Economy: how to people make money from ideas". Nova York. The Penguin Press.

Howlett, Michael., \& Ramesh, M., Perl. Anthony. (2009). "Studying Public Policy". Policy Cycles \& Policy Subsystems. 3td ed. Oxford.

Landry, Charles. Prefácio. In: REIS, Ana Carla Fonseca; Kageyama, Peter. (Orgs.). (2011). Cidades Criativas - Perspectivas. 1a ed. São Paulo: Garimpo de Soluções \& Creative Cities Productions. p. 7-15.

Pires, Vladimir Sibylla., \& Albagli, Sarita. (2012). “Estratégias empresariais, dinâmicas informacionais e identidade de marca na economia criativa". Perspect. ciênc. inf. [online]. vol.17, n.2, p. 109-122.

Salamon, Lester. (2002). "The Tools of Government: A Guide to the New Governance". New York: Oxford University Press.

Tortora, M. (2004). "Das idéias à ação: o papel catalisador da UNCTAD na geração da problemática do Desenvolvimento". Revista Puentes, v. 04. p. 1415

Saad, D.S. et al. (2012). "Economia criativa: fomento para o desenvolvimento regional". Congresso internacional interdisciplinar em sociais e humanidades. Niterói RJ: ANINTER-SH/ PPGSD-UFF. 
Simões, Janaina., \& Viera, Marcelo. (2010). "A influência do Estado e do mercado na administração da cultura no Brasil entre 1920 e 2002". Rio de Janeiro. Revista de Administração Pública.

Silva, Frederico Barbosa. (2007). "Política Cultural no Brasil, 2002-2006: acompanhamento e análise". Ministério da Cultura.

Smith, Steven Rathgeb., \& Ingram, Helen. (2002). "Policy Tools and Democracy", in Lester Salamon (ed.), The Tools of Government: A Guide to the New Governance. New York: Oxford University Press.

Tylor, Eduard. (1903). "Primative culture: researches into the development of mythology, philosophy, religion, language, art and custom". OISE - University of Toronto.

Wachowicz, Marcos.; \& Cruz e Silva, Rodrigo. (2011). "Direito autoral e economia criativa: a construção de uma economia preocupada com a criatividade". Liinc em Revista, v.7, n.2. Rio de Janeiro, p. 556 - 572. Disponível em: < http://revista.ibict.br/liinc/index.php/liinc/article/viewFile/442/323>. 